\title{
Determinants of plasma homocysteine in coal miners
}

\author{
A. Görkem Mungan ${ }^{\bowtie}$, Murat Can¹, Sibel Kıran², Şerefden Açıkgöz and Berrak Güven \\ 1Bulent Ecevit University, School of Medicine, Department of Medical Biochemistry, School of Medicine, Bulent Ecevit University, Zonguldak, \\ Turkey; ${ }^{2}$ Bulent Ecevit University, School of Medicine, Department of Public Health, School of Medicine, Bulent Ecevit University, Zonguldak, \\ Turkey
}

\begin{abstract}
Aim: Several studies suggest that coal miners are under risk of severe health problems such as cardiovascular, pulmonary, neurological, renal, hematological and musculoskeletal disorders. However, there are limited data on biochemical changes in underground workers. In our study we aimed to evaluate the association between serum homocysteine (Hcy), vitamin $B_{12}$, cystatin C and folate levels in the blood of underground coal miners. Materials and Methods: Eighty one coal miners who work as underground or surface workers were recruited into our study. The study population was divided into two groups: the surface worker group (control group, $n=33)$ and the underground worker group $(n=48)$. The folate, vitamin $B_{12}$, Hcy, cystatin C levels and body mass indexes (BMI) of both groups were measured and compared. Serum folate, Hcy and vitamin $B_{12}$ levels were measured with a competitive chemiluminescence immunassay. Serum levels of cystatin $C$ were determined by the latex particle-enhanced turbidimetric method using a cystatin C kit. Urea values were measured with a kinetic method on an automated analyzer. Results: There were no statistically significant differences between the underground workers and surface workers in the urea, cystatin $C$ and vitamin $B_{12}$ levels. High serum Hcy levels and low folate levels were found in underground workers compared with those in surface workers. The correlation between Hcy and folate levels was also statistically significant. Similarly, there was also a significant correlation between Hcy and vitamin $B_{12}$, and between Hcy and cystatin C levels. Conclusions: Elevated Hcy levels may be associated with underground working but further research is necessary to understand the relation between elevated Hcy and increased prevalence of health problems in coal miners.
\end{abstract}

Key words: coal miners, homocysteine, cystatin $\mathrm{C}$, vitamin $\mathrm{B}_{12}$, folate Received: 22 March, 2013; revised: 28 June, 2013; accepted: 15 July, 2013; available on-line: 25 July, 2013

\section{INTRODUCTION}

Mining has independently been associated with a number of adverse health effects such as cardiovascular, pulmonary, neurological, renal, hematological and musculoskeletal disorders. However, the effect of mining activities has not been adequately studied.

Homocysteine (Hcy) is a sulfur- containing, nonproteinogenic amino acid biosynthesized from methionine that occupies a key place between the folate and activated methyl cycles. Homocysteine has three metabolic fates: to be remethylated to methionine, to enter the cysteine biosynthetic pathway, or to be released into the extracelluler medium (Medina et al., 2001; Selhub et al., 1999). In adults Hyperhomocysteinemia (HHcy), is caused mainly by folate and vitamin $\mathrm{B}_{12}$ deficiency or polymorphism in the homocysteine metabolic pathway and leads to adverse health problems similar to those observed in coal miners (Sawuła et al., 2009).

Hcy might cause endothelial damage, generate free radicals, and promote oxidative damage and stress $(\mathrm{Ko}-$ nukoglu et al., 2003; Lewington et al., 2012; Kado et al., 2002). Folate is a B-vitamin that, as per definition of a vitamin, cannot be synthesized de novo; it must be derived from the diet or supplementation (Blom et al., 2011). The folate-mediated one-carbon metabolic pathway is fundamental to DNA synthesis, repair, and methylation (Collin et al., 2010). Biologically, this has been ascribed to the fact that inadequate intake of folate, vitamin $\mathrm{B}_{6}$, vitamin $\mathrm{B}_{12}$, or a combination of $\mathrm{B}$ vitamins increases Hcy levels. Epidemiological data also suggest that low folate levels pose a risk of cardiovascular diseases, several cancers and chronic diseases (Sauer et al., 2009).

Several studies have reported a positive relationship between Hcy levels, folate levels and heavy metals. The term "Heavy metal" refers to any metallic chemical element that has a high density and is toxic or poisonous at low concentrations. Coal contains many heavy metals, as it is created through compressed organic matter containing virtually every element in the periodic table - mainly carbon, but also heavy metals. The heavy metal content of coal varies by coal seam and geographic region. A variety of chemicals (mostly metals) associated with coal are either found in the coal directly or in the layers of rock that lie above and between the seams of coal (Vassilev et al., 2003; Vassilev et al., 2005). Furthermore, the coal miners work 8 hours shifts under heavy and troublesome conditions. Accessing the underground ore can be achieved via a decline (ramp), inclined vertical shaft or adit. These reach up to 2000 meters deep below the sea surface. The miners do continuous intensive physical work, encounter toxic fumes, and coal dust particles, and pressure changes at this altitude. All these parameters could impair serum Hcy and folate levels in coal miners.

However, to the best of our knowledge, there has been no study in the literature which investigates Hcy, cystatin $\mathrm{C}$, vitamin $\mathrm{B}_{12}$ and folate levels in coal miners. Zonguldak has been the main coal extraction basin of Turkey since the end of the 19th century. We compared

e-mail: agmungan@yahoo.com

Abbreviations: AdenosylMet, adenosylmethionine, AdenosylHcy, adenosylhomocysteine, BMI, body mass Index, Cr-EDTA, chromium(ethane-1,2-diyldinitrilo)tetraacetic acid, CVs, coefficients of variations, DNA, deoxyribonucleic acid, GFR, glomerular filtration rate, $\mathrm{Hcy}$, homocysteine, HHcy, hyperhomocysteinemia, 5MTHF, 5-methyltetrahydrofolate, UV, ultraviolet. 
the Hcy, urea, cystatin C, vitamin $\mathrm{B}_{12}$ and folate levels of underground coal mine workers with those of surface coal miners in the Zonguldak basin in order to investigate the effect of underground working on serum Hcy, urea, cystatin $\mathrm{C}$, vitamin $\mathrm{B}_{12}$ and folate levels.

\section{MATERIALS AND METHODS}

Study design. In total, 81 coal miners who work in Zonguldak coal mines as underground or surface workers were recruited into our study. All coal miners were male. The study population was divided to two groups: a surface worker group (control group) and an underground worker group. Thirty three men with a mean age of $42.8 \pm 5.4$ years (range: 36-48) who were healthy according to their medical histories, a basic examination and a rutine serum analysis, were enrolled into the surface worker group. The underground worker group consisted of 48 males with a mean age of $43.1 \pm 3.9$ years (range: $37-52$ years). The population of underground workers consisted of excavators $(n=8)$, transporters $(n=13)$, mechanics $(n=8)$, repairmen $(n=11)$ and others $(n=8)$. The mean total duration of underground work (total exposure) was $17.4 \pm 3.0$ years (range: $7-24$ years). The folate, vitamin $\mathrm{B}_{12}$, Hcy, cystatin $\mathrm{C}$ levels and body mass indexes (BMI) of both groups were measured.

Cigarette smoking, alcohol consumption, detailed medical history and drug intake (especially regarding to the use of medication related to the systemic diseases such as hyperlipidemia, hypertension, Diabetes Mellitus) were recorded and these patients were excluded.

Biochemical markers. Blood samples were taken in the morning under standardized conditions after an overnight fasting period. Serum samples were immediately centrifuged at $4{ }^{\circ} \mathrm{C}$ and stored at $-40^{\circ} \mathrm{C}$ until analysis. Serum folate and vitamin $\mathrm{B}_{12}$ levels were measured with a competitive chemiluminescence immunoassay (DPC Immulite 2000, BioDPC, Los Angeles/U.S.A.). Analytical sensitivity was $0.3 \mathrm{ng} / \mathrm{ml}$ and $50 \mathrm{pg} / \mathrm{ml}$, respectively. The intra- and inter assay coefficients of variations (CVs) were both below 4.1\%. Serum Hcy levels were measured by competitive chemiluminescence immunoassay with

Table 1. Characteristics of study population

\begin{tabular}{llll}
\hline & $\begin{array}{l}\text { Underground workers } \\
(\mathrm{n}=48)\end{array}$ & $\begin{array}{l}\text { Surface workers } \\
(\mathrm{n}=33)\end{array}$ & $P$ value \\
\hline Duration of work (years) & $17.4 \pm 3.0$ & $19.4 \pm 5.1$ & $>0.05$ \\
\hdashline Age (years) & $43.1 \pm 3.9$ & $42.8 \pm 5.4$ & $>0.05$ \\
\hline BMl $\left(\mathrm{kg} / \mathrm{m}^{2}\right)$ & $27.9 \pm 3.6$ & $25.6 \pm 3.9$ & $>0.05$ \\
\hline
\end{tabular}

Table 2. Cystatin C, urea and vitamin B12 levels

\begin{tabular}{llll}
\hline & $\begin{array}{l}\text { Underground workers } \\
(\mathrm{n}=48)\end{array}$ & $\begin{array}{l}\text { Surface workers } \\
(\mathrm{n}=33)\end{array}$ & $P$ value \\
\hline Cystatin C $(\mathrm{mg} / \mathrm{L})$ & $0.70 \pm 0.12$ & $0.69 \pm 0.38$ & $>0.05$ \\
\hdashline Urea $(\mathrm{mg} / \mathrm{dL})$ & $30.6 \pm 6.1$ & $29.2 \pm 8.0$ & $>0.05$ \\
\hline Vitamin $\mathrm{B} 12(\mathrm{pg} / \mathrm{mL})$ & $252.0 \pm 74.4$ & $257.0 \pm 90.8$ & $>0.05$ \\
\hline
\end{tabular}

Table 3. Homocysteine and folate levels

\begin{tabular}{llll}
\hline & $\begin{array}{l}\text { Underground workers } \\
(\mathrm{n}=48)\end{array}$ & $\begin{array}{l}\text { Surface workers } \\
(\mathrm{n}=33)\end{array}$ & $P$ value \\
\hline Folate $(\mathrm{ng} / \mathrm{mL})$ & $9.0 \pm 3.5$ & $13.3 \pm 1.0$ & $<0.05$ \\
\hline Homocysteine $(\mu \mathrm{mol} / \mathrm{L})$ & $13.5 \pm 9.5$ & $8.5 \pm 0.5$ & $<0.05$ \\
\hline
\end{tabular}

DPC Immulite 2000 (BioDPC, Los Angeles/U.S.A.). Analytical sensitivity was $0.5 \mu \mathrm{mol} / \mathrm{L}$. The intra- and inter assay coefficients of variations (CVs) were below $4.3 \%$. Serum levels of cystatin $\mathrm{C}$ were determined by the latex particle-enhanced turbidimetric method using a cystatin C kit (DAKO, Glostrup, Denmark) on a Cobas Integra 800 autoanalyser instrument (Roche, Mannheim, Germany) according to the manufacturer's instructions. The absorbance was measured at $552 \mathrm{~nm}$, and the cystatin C concentration of each sample was calculated from the calibration curve. Urea values were measured with a kinetic method on a Roche Integra 800 automated analyzer.

Statistical analysis. Results were reported as means \pm standard deviation. Differences between the study and control groups were compared using Student's $t$ test. Pearson's correlation was used to verify the correlations in serum parameters. $p<0.05$, two tail, was considered significant. Statistical analyses were performed using the SPSS 13.0 version for Windows (Chicago, IL, USA).

\section{RESULTS}

The age, duration of work and BMI levels were comparable in both groups $(p>0.05, p>0.05, p>0.05$, respectively) and data are given in Table 1 . In the present study, Hcy levels were significantly increased in underground workers compared to surface workers (13.5 \pm 9.5 , $8.5 \pm 0.5, p<0.05)$. Additionally, folate levels were significantly reduced in coal miners compared to those in control group $(9.0 \pm 3.5,13.3 \pm 1.0, p<0.05)$. There was no statistically significant difference between the underground workers and surface workers regarding the urea $(30.6 \pm 6.1,29.2 \pm 8.0, p>0.05)$, cystatin C (0.70 \pm 0.12 , $0.69 \pm 0.38, \quad p>0.05)$ and vitamin $B_{12} \quad(252.0 \pm 74.4$, $257.0 \pm 90.8, p>0.05$ ) levels (Table 2). The correlation between Hcy and folate levels was also statistically significant ( $\mathrm{r}=-0.297, p=0.014)$. Similarly, there was also a correlation between Hcy and vitamin $\mathrm{B}_{12}$, and between Hcy and cystatin $\mathrm{C}(\mathrm{r}=-0.371 \quad p=0.021$ and $\mathrm{r}=0.293$ $p=0.031$, respectively). There was no significant correlation between age and Hcy levels $(\mathrm{r}=0.039, p=0.747)$, age and folate $(\mathrm{r}=0.168, p=0.117)$. There was no significant correlation between the duration of work underground and Hcy levels $(r=0.135, p=0.420)$, or the duration of work underground and folate $(\mathrm{r}=0.238, p=0.156)$.

\section{DISCUSSION}

Epidemiological and clinical trials suggest that underground workers, particularly the coal miners, are under risk of severe health problems (Kado et al., 2002; Blom et al., 2011; Collin et al., 2010; Sauer et al., 2009). However, there are limited data on biochemical changes in underground workers. In the literature, there are only 1616 papers about coal miners. If you search for "coal miners health" in the PubMed, you will obtain less than 400 studies. When you search for "coal miners and biomarker" in PubMed, less than 200 articles will be found. 


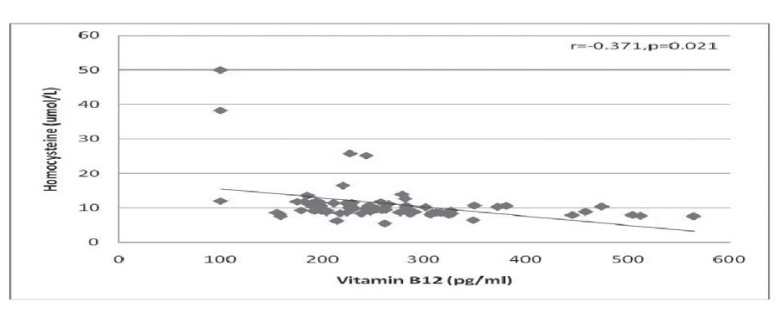

Figure 1. The relationship between homocysteine and vitamin B12.

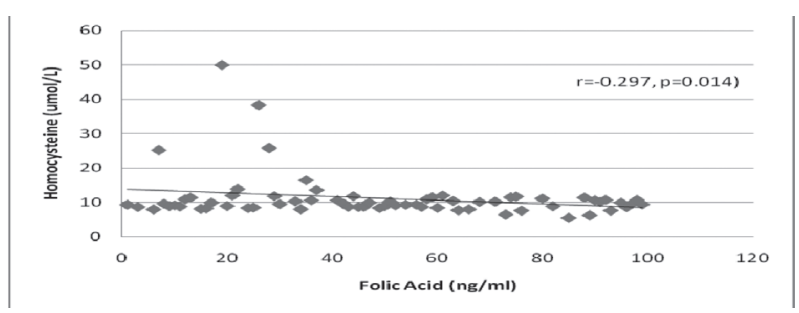

Figure 2. The relationship between homocysteine and folic acid.

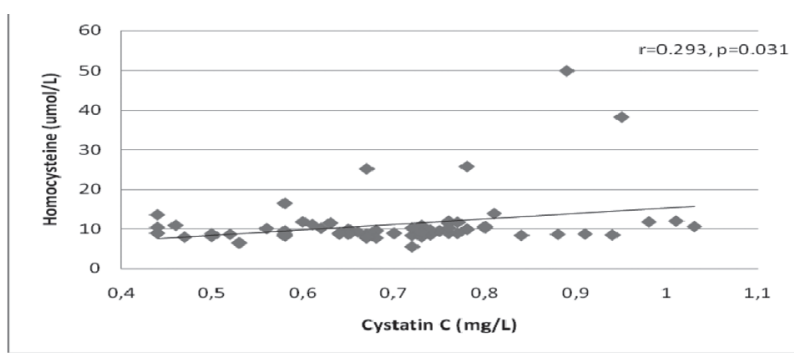

Figure 3. The relationship between homocysteine and cystatin C.

Our article is the first study in the literature which investigates Hcy, vitamin $B_{12}$ and folate levels in coal miners.

Theoretically An increase in plasma Hcy level could be caused by an increased production rate (i.e, transmethylation), a decreased rate of removal by transsulfuration or remethylation, or a decrease in the excretion of Hcy (Barrera-Chimal et al., 2012; Salgado et al., 2010). Current evidence indicates that the major mechanism for HHcy in renal failure is a decrease in Hcy removal from the body. However, it is debated whether this effect is the result of a decrease in the renal metabolic clearance or a result of extrarenal metabolic changes. The human kidney plays a major role in the removal of several aminothiols or Hcy-related compounds from the circulation (e.g., cysteine-glycine, glutathione, AdenosylMet, and AdenosylHcy) (Barrera-Chimal et al., 2012; Salgado et al., 2010). There is reasonably good clinical evidence that HHcy itself does not cause renal insufficiency (van Guldener et al., 2003). Several methods have been applied to investigate kidney and whole-body sulfur amino acid metabolism in healthy subjects and in patients with different degrees of renal failure (Perna et al., 2001). Blood urea and creatinine, the most widely used clinical markers of kidney function, are now recognized as an unreliable measure of GFR because serum urea and creatinine are affected by age, weight, muscle mass, race, various medications, hydration, diet, and extra-glomerular elimination (Garibotto et al., 2006). Cystatin C is an endogenous glycosylated protein produced in all nucleated cells in the human body and a novel marker for renal function (Laterza et al., 2002). The use of cystatin $C$ for the assessment of renal filtration function has recently been approved (Filler et al., 2005).

Serum creatinine, a surrogate for both renal function and Hcy generation, is a determinant of fasting plasma total Hcy levels (Bostom et al., 1999). Consistent results now clearly indicate that serum cystatin $C$ is superior to serum creatinine in early detection of a decrease in the glomerular filtration rate. There is a strong, independent (inverse) association between the glomerular filtration rate, directly determined by either thiohexol clearance or Cr-EDTA clearance, and fasting serum Hcy levels, which encompasses glomerular filtration rates throughout the normative range. These data also revealed that serum creatinine was not an independent predictor of fasting Hcy levels in models that included directly measured glomerular filtration rate. Serum cystatin C was a much better predictor of fasting Hcy levels relative to serum creatinine (Filler et al., 2005; Aras et al., 2001). Therefore, we studied cystatin $\mathrm{C}$ and urea levels in all participants to correctly detect Hcy level and properly evaluate the underlying mechanisms. In the present study, despite increased Hcy levels, cystatin $\mathrm{C}$ and urea levels were found to be in the normal range.

On the other hand, Hcy levels show a significant inverse correlation with serum vitamin $\mathrm{B}_{12}, \mathrm{~B}_{6}$ and folate levels. Individuals with low folate levels may have elevated levels of homocysteine. In this study, the same correlation between low levels of folate and high homocysteine levels were seen.

It is documented that the plasma Hcy levels are affected by physical activity. However, the data concerning the physical activity effect on plasma Hcy are equivocal since both a decrease and an increase in plasma Hcy have been noted in response to physical stress (Papapanagiotou et al., 2011). At present, data are scarce with regard to the effects of exercise on Hcy levels. Regular aerobic exercise lowers Hcy levels in overweight/obese persons by as much as $26 \%$ over the course of a 6 -month brisk walking program (three to five times per week) (Vincent et al., 2006; Randeva et al., 2002). Smaller but significant reductions $(6 \%$ to $8 \%)$ have been reported in healthy older adults after either a low- or high-intensity 24-week resistance training program (Vincent et al., 2003). Vincent et al. (2006) showed that overweight/obese older adults demonstrated $6 \%$ reduction in Hcy after resistance exercise, and normal-weight older adults demonstrated $12 \%$ reduction in Hcy after resistance exercise training. Also, the change in muscle strength was correlated with serum Hcy levels, whereas the change in adiposity was not $(\mathrm{r}=-0.264, p=0.095)$. In that study, authors pointed out several clinically important ramifications for the resistance exercise. First, reduction in Hcy lowers cardiovascular disease risk. Second, reduction in Hcy may normalize cell oxidation-reduction status and suppress prooxidant pathways that cause oxidative stress (Kado et al., 2002). Given that lipid peroxidation and Hcy levels were both reduced after resistance exercise training, it is possible that Hcy may mediate pathways that lead to oxidative stress reduction. Third, Kado et al. (2002) postulated that aging-induced skeletal muscle atrophy and weakness may be attenuated with reductions in Hcy. Coal miners work in the same manner as people doing resistance exercise, digging, lifting heavy stuff, drilling etc. However, these arguments could not explain high levels of Hcy in coal miners. Resistance exercise has been shown to improve insulin sensitivity in overweight individuals (Vincent et al., 2006; Ibanez et al., 2005) and may, therefore, increase Hcy clearance and reduce the blood levels of this amino acid. Also, resistance training that includes 
concentric muscle contractions, may cause transient hyperinsulinemia and increased net protein synthesis (Evans, 2004) in skeletal muscle in persons who are not insulin-resistant (Tessari et al., 2005). In our study, BMI of underground coal miners was found to be above 25 , probably due to increased muscle strength, which was slightly higher than that of surface workers (not statistically significant). However the BMI value could not be a sufficient explanation for increased Hcy levels in underground workers. In our study population, all workers (both underground and surface) have been working for more than 15 years. The effect of cumulative years (more than 10 years) of working under extreme conditions on Hcy levels has not been addressed.

Although specific aspects of Hcy kinetics were not measured in this study, we speculate that there are potential resistance exercise induced mechanisms that may contribute to the alteration in Hcy levels. However, data concerning the physical activity effect on plasma Hcy concentration are equivocal since both a decrease and an increase in plasma Hcy have been noted in response to physical stress (Ruiz et al., 2007). Football and field hockey are high-intensity intermittent sports that rely predominantly on aerobic energy pathways but also involve a considerable amount of anaerobic activities. Analysis of the physiological cost and energy expenditure of hockey and football players have placed these games in the category of heavy exercise (Reilly et al., 1992). Papapanagiotou et al (2011) investigated the levels of Hcy in football and hockey players before and soon after a match. All the athletes presented significant increases in serum Hcy levels soon after a match $(p=0.001$ for football and $p=0.001$ for hockey players). A cross-sectional study in 434 Japanese adults examined the associations among objectively measured physical activity, plasma Hcy adjusted for dietary folate intake, and MTHFR C677'T genotype (Murakami et al., 2011). In some genotypes (T'T), a shorter time spent in light physical activity was associated with higher plasma Hcy than a longer time spent in light physical activity $(11.5 \pm 3.3 \mathrm{nmol} / \mathrm{mL} v$ s. $8.5 \pm 3.3 \mathrm{nmol} / \mathrm{mL}, p<0.001)$. Venta et al. (2009) showed higher plasma concentrations of Hcy after an acute intense exercise too, but no changes were seen in folate levels. However, evidence gathered from long-term exercise training, which includes moderate and high-intensity levels, is equivocal. Therefore, Hcy kinetics should be investigated for coal miners at regular intervals, e.g., at the end of the working day in the first months of working, to facilitate a correct interpretation. It may be useful for reorganizing their working program.

The low folate levels were found in underground workers compared with surface workers $(9.0 \pm 3.5$ and $13.3 \pm 1.0$, respectively, $p<0.05)$. It is hard to interpret this finding because there is no research about this issue. Some hypotheses could be put forward about low folate levels in coal miners working underground.

One of the most important aspects of underground hard rock mining is ventilation. Ventilation is required to clear toxic fumes and remove exhaust fumes from diesel equipment. Coal miners are highly exposed to coal dust particles. Chronic occupational exposure to coal dust particles can result in a broad range of adverse effects. In the coal basin in which the study was performed, mean respirable dust concentrations underground and on the ground were $1.66 \mathrm{mg} / \mathrm{m}^{3}$ and $0.73 \mathrm{mg} / \mathrm{m}^{3}$, respectively. Incidence of pneumoconiosis ranged between $0.17-2.8$ percent and the prevalence ranged between 1.23-6.23 percent between 1985 and 2004 (Tor et al., 2010). Landen et al. (2011) examined the dose-response relationship between cumulative coal dust exposure, coal rank, and ischemic heart disease mortality among a cohort of underground coal miners who participated in the National Study of Coal Workers' Pneumoconiosis. There was an increased risk of mortality from ischemic heart disease associated with cumulative exposure to coal dust and with coal rank. They concluded that the effect of coal rank could be due to differences in the composition of coal mine dust particles. In some studies, occupational exposure to some inorganic particles such as chromate was associated with vitamin $\mathrm{B}_{12}$ and folate deficiency. Chrome and related compounds such as chromate are found in the coal in the range of $10-220 \mathrm{mg} / \mathrm{kg}$ (Takahashi et al., 1989). When the coal is heated, chrome and chromate are found both as airborne solid particles and in a gaseous form in the air. Wang et al (2011) showed that serum vitamin $\mathrm{B}_{12}$ and folate levels were decreased and significantly inversely correlated with chromium concentrations in red blood cells in the chromate exposed workers. The same authors also found that oxidative DNA damage and global DNA hypomethylation were related to folate deficiency in chromate manufacturing workers (Wang et al., 2012). The results showed an evident accumulation of Chrome in erythrocyte accompanied by significantly decreased serum folate in chromate exposed workers. The decreased serum folate was associated with increased urinary 8-hydroxy-2'-deoxyguanosine, DNA strand breaks and global DNA hypomethylation. These findings suggest that chronic occupational chromate exposure could induce folate depletion, which may further promote DNA damages and global DNA hypomethylation. However, the metabolic consequences of coal particle exposure have not been fully investigated. Further studies designed to correlate the risk of low folate levels with coal particle exposure are needed to evaluate this issue.

On the other hand, several recent studies have reported a positive relationship between blood lead and Hcy levels in the general population or lead-exposed workers, suggesting that certain kinds of heavy metals can disturb the metabolism of Hcy (Lee et al., 2012; Chia et al., 2007). Notably, micronutrients such as folate, vitamin $\mathrm{B}_{6}$, and vitamin $\mathrm{B}_{12}$ are also involved in the pathways of Hcy metabolism (Lee et al., 2012). Therefore, it is postulated that there may be some joint effect of heavy metal exposition and these micronutrients on the level of Hcy. Many of the heavy metals released in the mining and burning of coal, such as lead, mercury, nickel, tin, cadmium, antimony, and arsenic, as well as radio isotopes of thorium and strontium, are environmentally and biologically toxic elements (Vassilev et al., 2003). The relation between heavy metals and folate were also studied by several investigators. In vitro studies found that mercury inhibited methionine synthase, an enzyme that interacts with vitamin $\mathrm{B}_{12}$ and folate to regenerate the amino acid methionine from Hcy, and inhibition of methionine synthase diverted Hcy to cysteine and glutathione synthesis. Gallagher et al. (2011) showed that $\mathrm{Hg}$ was inversely correlated with plasma Hcy, with higher methylmalonic acid and lower folate. Krieg et al. (2009) pointed out that serum folate, erythrocyte folate, and serum vitamin $\mathrm{B}_{12}$ decreased as the blood lead concentration increased. Katko et al. (2008) suggested that nickel might also be involved in the regulation of the methionine-folate cycle in humans. Tamura et al. (2004) indicated that longterm, high-copper intake resulted in small but significant decreases in plasma concentrations of Hcy and folate. Heavy metals released in mining could be the explanation of low folate levels in underground coal miners. 
However, blood and tissue levels of each heavy metal which is present in the coal should be studied in coal miners to properly understand the possible effects of these heavy metals on Hcy, vitamin $\mathrm{B}_{12}$ and folate levels.

The second hypothesis concerns solar radiation. Solar radiation and human health has been one of the hottest topics within the fields of photochemistry and photomedicine for 20 years worldwide. The photodegradation of folic acid, a synthetic form of folate, has been thoroughly studied (Steindal et al., 2006; Steindal et al., 2008; Tam et al., 2009; Borradale et al., 2012). The relationship between UV radiation and folate degradation is complicated by the fact that UVB (ultraviolet B, 280-315 nm) radiation, while being able to degrade the main biological form of folate found in blood, 5-methyltetrahydrofolate (5MTHF), is unable to penetrate to the dermal circulation to impact its blood levels (Steindal et al., 2006; Tam et al., 2009). Conversely, the longer-wavelength UVA (ultraviolet A, 315-400 $\mathrm{nm}$ ) radiation is able to penetrate to the dermal circulation but it is unable to directly degrade 5MTHF (Steindal et al., 2008). Therefore, no definite conclusion about the possibility of folate photodegradation under artificial UV sources has been drawn. As a first step in the elucidation of this problem, investigations of the photophysics and photochemistry of folate in simple model systems would be of great value. The second step would be to investigate the possible effect of underground working under artificial UV sources on the folate level because coal miners, who cover their entire skin with clothes, spend 8 hours underground under artificial UV sources.

The third hypothesis is focused on differences in folate status relative to the body mass index. In the our study, although there was no statistically significant difference in BMI between two groups $(p>0.05)$, BMI of underground workers was slightly higher than BMI of surface workers $(27.9 \pm 3.6$ vs $25.6 \pm 3.9)$. In recent studies, the concentration of folate has been suggested to be negatively correlated with BMI(Nakazato et al., 2011; Stern et al., 2012; Tinker et al., 2012). Nakazato et al. measured plasma and erythrocyte folate and plasma Hcy concentrations in 434 healthy adults (343 women and 91 men; range 23-88 years), who participated in a 2007 population-based survey in western Japan (Papapanagiotou et al., 2011). The overall mean plasma and erythrocyte folate levels were 21.6 ( \pm 11.0, S.D.) nmol/L and 844 ( \pm 291$) \mathrm{nmol} / \mathrm{L}$, respectively. The mean BMI was $22.8( \pm 3.0 ; 15.6-33.3) \mathrm{kg} / \mathrm{m}(2)$, and only 72 subjects $(17 \%)$ had BMI $>26.0 \mathrm{~kg} / \mathrm{m}(2)$. Mean plasma folate decreased as BMI increased ( $p$-trend $<0.01)$, whereas mean erythrocyte folate was similar regardless of BMI ( $p$ trends $=0.49)$. Tinker et al. (2012) pointed out that BMI may affect the body distribution of folate, as also reflected by lower serum and higher erythrocyte folate levels.

On the other hand, our results may be misleading because we analysed solely the serum folate levels. For determining folate status, the following parameters are used: serum folate and erythrocyte folate. Serum folate provides a short-term assessment of folate status and isthus, a determinant of recent folate intake, while erythrocyte folate provides a longer-term assessment of folate status (past 2-3 months of intake) (Hughes et al., 2000). Traditionally, immunoassay methods have been used to test folate status, but this technique is unable to distinguish between different folate metabolites and to detect the presence of unmetabolized folic acid in the circulation (Hughes et al., 2000; Kalmbach et al., 2011). Furthermore, the assay of erythrocyte folate has many technical pitfalls: both the interlaboratory variation and the coef- ficient of variation have been high. Therefore, further studies which investigate and compare both serum folate and erythrocyte folate are needed for coal mining workers.

The fourth hypothesis concerns the influence of altitude, pressure changes and diverse oxygen environments on the folate level. Our study population of coal miners works approximately $500 \mathrm{~m}$ below the sea level. This altitude difference could affect folate levels. Responses of humans to oxidative stressors were examined in participants undergoing a saturation dive in an environment with increased partial pressure of oxygen, a NASA Extreme Environment Mission Operations project (Zwart et al., 2012). Participants completed a 13-d saturation dive in a habitat $19 \mathrm{~m}$ below the ocean surface near Key Largo, FL. Fasting blood samples were collected before, twice during, and twice after the dive and analyzed for biochemical markers of iron status, oxidative damage, and vitamin status. Body iron stores and ferritin increased during the dive $(p<0.001)$, with a concomitant decrease in erythrocyte folate $(p<0.001)$ and superoxide dismutase activity $(p<0.001)$. Folate status decreased quickly in this environment. Adits and inclined vertical shafts reach up to 800 meters deep below the sea surface at the Zonguldak coal basin. Further research is needed to understand the possible effects of altitude, pressure changes and diverse oxygen environments on the folate level.

The last hypothesis proposes that low folate levels may be due to heavy working conditions and increased nutrition requirements. Ultra endurance exercise imposes large energy demands on coal miners and causes a high turnover of vitamins through sweat loss, metabolism, and the musculoskeletal repair process (Wani et al., 2008; Ueland et al., 1993; Yetley et al., 2011). Folate and vitamin $\mathrm{B}_{12}$ deficiency is often nutritional (Wani et al., 2008; Ueland et al., 1993; Rader et al., 2002). High endurance workers may not consume sufficient quantities or quality of food in their diet to meet these needs. Emphasis should also be placed on the dietary intake of certain micronutrients by the coal miners, as well as the potential need for supplementation of certain vitamins and minerals, including vitamins $\mathrm{B}_{2}, \mathrm{~B}_{6}, \mathrm{~B}_{12}, \mathrm{D}, \mathrm{E}$, and folate, and the minerals such as calcium and iron. The primary cause of folate deficiency is low intake of food rich in the vitamin, such as legumes and green leafy vegetables; consumption of these foods may explain why folate status can be adequate in relatively poor populations (Allen et al., 2008). In our study population, all the miners had normal level of vitamin $\mathrm{B}_{12}$. Therefore, low folate levels could not be adequately explained only as an effect of diet and vitamin $B_{12}$ levels. The influence of extensive physical exercise and acute intense exercise on plasma concentrations of folate should be investigated in detail in coal miners and other heavy workers. On the other hand, a "study of the effectiveness of additional reduction in cholesterol and homocysteine" (SEARCH) pointed out that folic acid and B-vitamins supplementation have no beneficial effects on the risk of diseases, although Hcy concentration lowered (Study of the Effectiveness of Additional Reductions in Cholesterol and Homocysteine (SEARCH) Collaborative Group, 2010). Detailed and well designed studies have reached the same results (Ford et al., 2012; Holmes et al., 2011). These studies have shown the importance of understanding the underlying mechanisms of low folate levels in underground coal miners.

In our study, low folate, elevated Hcy and normal vitamin $\mathrm{B}_{12}$ levels were found in coal miners. It is dif- 
fucult to explain the underlying mechanisms because no research has been done before about this issue. Consequently, further studies are necessary to more completely understand the risk of working in underground coal mines and delineate what characteristics of these employees put them at risk of work related morbidity and mortality.

\section{REFERENCES}

Allen LH (2008) Causes of vitamin B12 and folate deficiency. Food Nutr Bull 29: 20-34.

Aras O, Tsai MY, Hanson NQ, Bailey R, Rao G, Hunninghake DB (2001) Cystatin $\mathrm{C}$ is an independent predictor of fasting and postmethionine load total homocysteine concentrations among stable renal transplant recipients. Clin Chem 47: 1263-1268.

Barrera-Chimal J, Bobadilla NA (2012) Are recently reported biomarkers helpful for early and accurate diagnosis of acute kidney injury? Biomarkers 17: 385-393.

Blom HJ, Smulders Y (2011) Overview of homocysteine and folate metabolism With special references to cardiovascular disease and neural tube defects. I Inherit Metab Dis 34: 75-81

Borradale DC, Kimlin MG (2012) Folate degradation due to ultraviolet radiation: possible implications for human health and nutrition. Nutr Rev 70: 414-422.

Bostom AG, Bausserman L, Jacques PF, Liaugaudas G, Selhub J, Rosenberg IH (1999) Cystatin C as a Determinant of Fasting Plasma Total Homocysteine Levels in Coronary Artery Disease Patients With Normal Serum Creatinine. Arterioscler Thromb Vasc Biol 19: 2241-2244.

Chia SE, Ali SM, Lee BL, Lim GH, Jin S, Dong NV et al. (2007) Association of blood lead and homocysteine levels among lead exposed subjects in Vietnam and Singapore. Occup Environ Med 64: 688-693.

Collin SM, Metcalfe C, Refsum H, Lewis SJ, Zuccolo L, Smith GD et al. (2010) Circulating folate, vitamin B12, homocysteine, vitamin B12 transport proteins, and risk of prostate cancer: a case-control study, systematic review, and meta-analysis. Cancer Epidemiol Biomarkers Prev 19: 1632-1642.

Evans, WJ (2004) Protein nutrition, exercise and aging. J Am Coll Nutr 23: 601-609.

Filler G, Bökenkamp A, Hofmann W, Le Bricon T, Martínez-Brú C, Grubb A (2005) Cystatin C as a marker of GFR: History, indications, and future research. Clin Biochem 38: 1-8.

Ford AH, Almeida OP (2012) Effect of homocysteine lowering treatment on cognitive function: a systematic review and meta-analysis of randomized controlled trials. J Alzheimers Dis 29: 133-149

Gallagher CM, Meliker JR (2011) Total blood mercury, plasma homocysteine, methylmalonic acid and folate in US children aged 3-5 years, NHANES 1999-2004. Sci Total Environ 409: 1399-1405.

Garibotto G, Sofia A, Valli A, Tarroni A, Di Martino M, Cappelli V et al. (2006) Causes of hyperhomocysteinemia in patients with chronic kidney diseases. Semin Nephrol 26: 3-7.

Holmes MV, Newcombe P, Hubacek JA, Sofat R, Ricketts SL, Cooper J et al. (2011) Effect modification by population dietary folate on the association between MTHFR genotype, homocysteine, and stroke risk: a meta-analysis of genetic studies and randomised trials. Lancet 13: 584-594.

Hughes J, Buttriss J (2000) An update on folates and folic acid: Contribution of MAFF funded research. Nutr Bull 25: 113-124.

Ibanez J, Izquierdo M, Arguelles I, Forga L, Larrión JL, García-Unciti $\mathrm{M}$ et al. (2005) Twice-weekly progressive resistance training decreases abdominal fat and improves insulin sensitivity in older men with type 2 diabetes. Diabetes Care 28: 662-667.

Kado DM, Bucur A, Selhub J, Rowe JW, Seeman T (2002) Homocysteine levels and decline in physical function: MacArthur studies of successful aging. Am J Med 113: 537-542.

Kalmbach R, Paul L, Selhub J (2011) Determination of unmetabolized folic acid in human plasma using affinity HPLC. Am J Clin Nutr 94: 343-347.

Katko M, Kiss I, Karpati I, Kadar A, Matyus J, Csongradi E et al. (2008) Relationship between serum nickel and homocysteine concentration in hemodialysis patients. Biol Trace Elem Res 124: 195-205.

Krieg EF, Butler MA (2009) Blood lead, serum homocysteine, and neurobehavioral test performance in the third National Health and Nutrition Examination Survey. Neurotoxicology. 30: 281-289.

Konukoglu D, Serin O, Ercan M, Turhan MS (2003) Plasma homocysteine levels in obese and normal weight subjects with or without hypertension: its relationship with oxidative stress and copper. Clin Biochem 36: 405-408

Landen DD, Wassell JT, McWilliams L, Patel A (2011) Coal dust exposure and mortality from ischemic heart disease among a cohort of U.S. coal miners. Am J Ind Med 54: 727-733.
Laterza OF, Price CP, Scott MG (2002) Cystatin C: An improved estimator of glomerular filtration rate? Clin Chem 48: 699-707.

Lee YM, Lee MK, Bae SG, Lee SH, Kim SY, Lee DH (2012) Association of homocysteine levels with blood lead levels and micronutrients in the US general population. Prev Med Public Health 45: 387-393.

Lewington S, Bragg F, Clarke R (2012) A review on metaanalysis of biomarkers: promises and pitfalls. Clin Chem 58: 1192-1204.

Medina MÁ, Urdiales JL, Amores-Sànchez MI (2001) Roles of homocysteine in cell metabolism:Old and new functions. Eur J Biochem 268: 3871-3882.

Murakami H, Iemitsu M, Sanada K, Gando Y, Ohmori Y, Kawakami $\mathrm{R}$ et al. (2011) Associations among objectively measured physical activity, fasting plasma homocysteine concentration, and MTHFR C677T genotype. Eur J Appl Physiol 111: 2997-3005.

Nakazato M, Maeda T, Takamura N, Wada M, Yamasaki H, Johnston KE et al. (2011) Relation of body mass index to blood folate and total homocysteine concentrations in Japanese adults. Eur J Nutr 50: $581-585$.

Papapanagiotou A, Gissis I, Papadopoulos C, Souglis A, Bogdanis GC, Giosos I et al. (2011) Changes in homocysteine and 8-iso-PGF(2a) levels in football and hockey players after a match. Res Sports Med 19: $118-128$.

Perna AF, Ingrosso D, Satta E, Romano M, Cimmino A, Galletti P et al. (2001) Metabolic consequences of hyperhomocysteinemia in uremia. Am J Kidney Dis 38: 85-90.

Rader JI (2002) Folic acid fortification, folate status and plasma homocysteine. I Nutr 132: 2466-2470.

Randeva HS, Lewandowski KC, Drzewsoski J, Brooke Wavell K, O'Callaghan C, Czupryniak L et al. (2002) Exercise decreases plasma total homocysteine in overweight young women with polycystic ovary syndrome. I Endocrinol Metab 87: 4496-4501.

Reilly T, Borrie A (1992) Physiology applied to field hockey. Sports Med 14: $10-26$.

Ruiz JR, Hurting-Wennlof A, Ortega FB, Patterson E, Nilsson TK, Castillo MJ et al. (2007) Homocysteine levels in children and adolescents are associated with the methlenetetrahydrofolate reductase 677C $>$ T genotype, but not with physical activity, fitness or fatness: The European Youth Heart study. British Journal of Nutrition 97: 255-262.

Salgado JV, Neves FA, Bastos MG, França AK, Brito DJ, Santos EM et al. (2010) Monitoring renal function: measured and estimated glomerular filtration rates - a review. BrazJ Med Biol Res 43: 528-536.

Sauer J, Mason JB, Choi SW (2009) Too much folate: a risk factor for cancer and cardiovascular disease? Curr Opin Clin Nutr Metab Care 12: $30-6$.

Selhub J (1999) Homocysteine metabolism. Annu Rev Nutr 19: 217-246.

Steindal AH, Juzeniene A, Johnsson A, Moan J (2006) Photodegradation of 5-methyltetrahydrofolate: Biophysical Aspects. Photochemistry and Photobiology 82: 1651-1655.

Steindal AH, Tam TTT, Lu XYLu XY, Juzeniene A, Moan J (2008) 5-Methyltetrahydrofolate is photosensitive in the presence of riboflavin. Photochem Photobio 7: 814-818.

Stern SJ, Matok I, Kapur B, Koren G (2012) Dosage requirements for periconceptional folic acid supplementation: accounting for BMI and lean body weight. J Obstet Gynaecol Can 34: 374-378.

Study of the Effectiveness of Additional Reductions in Cholesterol and Homocysteine (SEARCH) Collaborative Group (2010) Effects of homocysteine lowering with folic acid plus vitamin B12 vs. placebo on mortality and major morbidity in myocardial survivors. A randomized trial. JAMA 303: 486-494

Takahashi R, Sasaki M (1989) Automatic macerals analysis of low rank coal. Int J Coal Geol 14: 103-118.

Tam TT, Juzeniene A, Steindal AH, Iani V, Moan J (2009) Photodegradation of 5-methyltetrahydrofolate in the presence of uroporphyrin. J Photochem Photobiol B 94: 201-204.

Tamura T, Turnlund JR (2004) Effect of long-term, high-copper intake on the concentrations of plasma homocysteine and B vitamins in young men. Nutrition 20: 757-759.

Tessari P, Coracina A, Kiwanuka E, Vedovato M, Vettore M, Valerio A et al. (2005) Effects of insulin on methionine and homocysteine kinetics in type 2 diabetes with nephropathy. Diabetes 54: 2968-2976.

Tinker SC, Hamner HC, Berry RJ, Bailey LB, Pfeiffer CM (2012) Does obesity modify the association of supplemental folic acid with folate status among nonpregnant women of childbearing age in the United States? Birth Defects Res A Clin Mol Teratol 94: 749-755.

Tor M, Oztürk M, Altın R, Cimrin AH (2010) Working conditions and pneumoconiosis in Turkish coal miners between 1985 and 2004: a report from Zonguldak coal basin, Turkey. Tuberk Toraks 58: 252260

Ueland PM, Refsum H, Stabler SP, Malinow MR, Andersson A, Allen RH (1993) Total homocysteine in plasma or serum: methods and clinical applications. Clin Chem 39: 1764-1779.

van Guldener C, Stehouwer CD (2003) Homocysteine metabolism in renal disease. Clin Chem Lab Med 41: 1412-1417. 
Vassilev SV, Menendez R, Alvarez D, Diaz-Somoano M, MartinezTarazona MR (2003) Phase-mineral and chemical composition of coal fly ashes as a basis for their multicomponent utilization. Characterization of feed coals and fly ashes. Fuel 82: 1793-1811.

Vassilev SV, Vassileva CG, Karayigit AI, Bulut Y, Alastuey A, Querol $\mathrm{X}$ (2005) Phase-mineral and chemical composition of fractions separated from composite fly ashes at the Soma power station, Turkey. Int I Coal Geology 61: 65-85.

Venta R, Cruz E, Valcarcel G, Terrados N (2009) Plasma vitamins, amino acids, and renal function in postexercise hyperhomocysteinemia. Med Sci Sports Exerc 41: 1645-1651.

Vincent KR, Braith RW, Bottiglieri T, Vincent HK, Lowenthal DT (2003) Homocysteine and lipoprotein levels following resistance training in older adults. Prev Cardiol 6: 197-203.

Vincent HK, Bourguignon C, Vincent KR (2006) Resistance training lowers exercise induced oxidative stress and homocysteine levels in overweight and obese older adults. Obesity 14: 1921-1930.
Wang TC, Jia G, Zhang J, Ma YH, Liu LZ, Zhang N et al. (2011) Vitamin B12 and folate deficiency and elevated plasma total homocysteine in workers with chronic exposure to chromate. Occup Environ Med 68: 870-875.

Wang TC, Song YS, Wang H, Zhang J, Yu SF, Gu YE et al. (2012) Oxidative DNA damage and global DNA hypomethylation are related to folate deficiency in chromate manufacturing workers. I Hazard Mater 30: 213-214.

Wani NA, Hamid A, Kaur J (2008) Folate status in various pathophysiological conditions. IUBMB Life 60: 834-842.

Yetley EA, Pfeiffer CM, Phinney KW, Fazili Z, Lacher DA, Bailey RI et al. (2011) Biomarkers of folate status in NHANES: a roundtable summary. Am J Clin Nutr 94: 303-312.

Zwart SR, Jessup JM, Ji J, Smith SM (2012) Saturation diving alters folate status and biomarkers of DNA damage and repair. PLoS One 7: e31058. 